\title{
Pendampingan Pada Komunitas Anak Disabilitas di Kota Pekanbaru Melalui Pemahaman Hak-Hak Aksessibilitas
}

\author{
Hengki Firmanda ${ }^{1}$, Emilda Firdaus ${ }^{2}$, Nabella Puspa Rani ${ }^{3}$ \\ 1) 2) 3) Universitas Riau, Indonesia \\ M Email : hengki.firmanda@gmail.com
}

Received: 11-01-2021

Revised: 21-03-2021

Accepted: 28-04-2021

\begin{abstract}
:
The first fact is still found by parents who have not paid special attention to children with disabilities, resulting in violations of the rights of children with disabilities. The second fact is that the legal instruments are still weak and the regulations have not been fully implemented. These facts are an inhibiting factor in the development of children with disabilities. The purpose of this activity is so that children with disabilities know what their rights are, so that children with disabilities still feel respected by their presence. The output of this activity is the fulfillment of accessibility rights for children with disabilities in their growth and development in the social environment. The result of this activity is that children with disabilities know their rights, so that discrimination against them is not allowed. Children with disabilities also know that they have special rights guaranteed by laws and regulations.
\end{abstract}

Keyword: Disability, Accessibility, Human Rights

\section{Pendahuluan}

Anak adalah amanah dan karunia Tuhan Yang Maha Esa yang dalam dirinya melekat harkat dan martabat sebagai manusia seutuhnya. Anak merupakan tunas, potensi dan generasi muda penerus cita-cita perjuangan bangsa, memiliki peran strategis dan mempunyai ciri dan sifat khusus yang menjamin kelangsungan eksistensi bangsa dan negara di masa depan. Ketentuan dalam Pasal 28B ayat (2) Undang-Undang Dasar 1945 menyebutkan bahwa setiap anak berhak atas kelangsungan hidup, tumbuh dan berkembang serta berhak atas perlindungan dari kekerasan dan diskriminasi.

Setiap anak mempunyai harkat dan martabat yang di lindungi oleh hukum. Perlindungan ini perlu karena anak merupakan bagian masyarakat yang mempunyai keterbatasan secara fisik dan mentalnya (Marliana, 2009). Oleh sebab itu anak memerlukan pembinaan dan perlindungan dalam rangka menjamin pertumbuhan dan perkembangan fisik, mental, dan sosial secara seimbang.

Secara Internasional, telah diatur dengan tegas bentuk perlindungan terhadap anak. Bentuk perlindungan terhadap anak dapat dilihat dari beberapa Konvensi Internasional tentang perlindungan terhadap anak, salah satunya yaitu Konvensi Perserikatan BangsaBangsa mengenai Hak Anak atau (Convention on the Rights of the Child) Tahun 1989 yang mengemukakan prinsip-prinsip umum perlindungan anak, yaitu non diskriminasi, 
kepentingan terbaik bagi anak, kelangsungan hidup dan tumbuh kembang, dan menghargai partisipasi anak.

Dalam konvensi hak-hak anak juga diatur mengenai prinsip perlindungan khusus terhadap anak. Hal ini disebabkan dalam tahap perkembangan, anak-anak akan mempelajari apa yang dilihat, didengar, dan dirasakan. Oleh karena itu anak memerlukan pembinaan dan bimbingan khusus agar dapat berkembang baik secara fisik, mental dan spiritualnya dengan maksimal (Darwan Prinst, 1997).

Perlindungan Anak sebagaimana dimaksud dalam Pasal 1 angka 2 Undang-Undang Nomor 35 Tahun 2014 tentang Perlindungan Anak, adalah segala kegiatan untuk menjamin dan melindungi anak dan hak-haknya agar dapat hidup, tumbuh, berkembang dan berpartisipasi secara optimal sesuai dengan harkat dan martabat kemanusiaan, serta mendapat perlindungan dari kekerasan dan diskriminasi.

The Committee Of National Society For The Study Of Education di Amerika Serikat mengatakan bahwa anak cacat adalah gerakan-gerakan yang menyimpang dari gerakan yang normal, walaupun telah dikembangkan secara maksimal. Penyimpangan tersebut dapat dilihat dari segi fisik, mental, tingkah laku, emosional, dan sosial.

Setiap anak berhak untuk dijamin, dilindungi, dan dihormati setiap hak yang melekat pada dirinya. Setiap anak berhak untuk mengembangkan potensi yang ada dalam dirinya dan orang tua wajib mendukung hal tersebut. Kita tidak hanya diwajibkan memperhatikan anak-anak gifted atau berbakat, tetapi juga anak-anak yang membutuhkan perhatian khusus seperti autisme, tunanetra, tunarungu, tunagharita, ataupun anak-anak dengan kelainan dan penyakit tertentu.

Banyak kasus-kasus pelanggaran Hak Asasi Manusia di Indonesia yang terjadi pada anak yang menjadi sorotan dan menyita perhatian publik. Banyak anak yang dijual, disiksa bahkan terkadang ada anak-anak yang terlahir dengan membawa penyakit turunan dari orang tua atau bahkan terkena gizi buruk. Hal yang demikian adalah potret yang sangat menyedihkan, anak yang seharusnya mendapatkan perhatian, kasih sayang dan cinta malah mendapatkan perlakuan yang tidak seharusnya ia rasakan.

Kehidupan masyarakat sangat berpengaruh terhadap kepribadian anak, dimana umumnya masyarakat tidak dapat menerima perlakuan anak yang melanggar aturan, sehingga masyarakat mencap anak sebagai pelaku kejahatan ataupun pelaku kenakalan, sehingga prilaku masyarakat terhadap anak membawa dampak buruk bagi masa depan anak (Romli Atmasasmita, 2007). Masyarakat juga masih banyak yang tidak memberikan perhatian khusus kepada anak penyandang disabilitas, bahkan masih ada yang menganggap bahwa penyandang disabilitas itu merupakan suatu kehinaan yang pantas untuk dijadikan bahan tertawaan.

Saat ini, masih ditemukan orang tua yang belum memberikan perhatian khusus kepada anak penyandang disabilitas, sehingga menimbulkan terjadinya pelanggaran terhadap hak-hak anak yang juga terdapat pada mereka. Perangkat hukum di negeri kita masih lemah, peraturan yang ada belum dilaksanakan secara penuh. Seharusnya kita bisa mencegah terjadinya pelanggaran terhadap Hak Asasi Manusia Anak. Anak-anak yang tidak berdosa, yang seharusnya diperhatikan dan dikasihani malah menjadi korban 
kekerasan. Sebagai orang tua, kendati kita tidak hafal secara persis apa-apa saja hak-hak anak penyandang disabilitas, seharusnya orang tua punya perasaan, naluri, dan akal sehat. Jadi, tanpa harus lebih dulu ada aturan hukumnya, sudah seharusnya kita memberikan yang terbaik untuk anak, tidak terkecuali pada anak penyandang disabilitas.

Kondisi tersebut merupakan salah satu faktor penghambat dalam tumbuh kembang anak disabilitas. Mardjono Reksodiputro dalam sebuah makalahnya menyatakan bahwa apabila ada pendapat yang menyatakan kalau perilaku delinkuen selalu akan membawa anak (baik pria maupun wanita) menjadi pelaku kejahatan atau penjahat di masa yang akan datang adalah keliru. Akan tetapi, beliau berpendapat bahwa masalah delinkuensi anak itu tidak ditangani dengan baik, maka pada masa yang akan datang dapat terjadi kenaikan tingkat kriminalitas dalam masyarakat (Nashriana, 2001).

Dengan demikian perlu adanya perubahan paradigma dalam penanganan anak penyandang disabilitas, antara lain didasarkan pada peran dan tugas masyarakat, pemerintah, dan lembaga negara lainnya yang berkewajiban dan bertanggung jawab untuk meningkatkan kesejahteraan anak penyandang disabilitas. Anak disabilitas juga merupakan anak, yang menjadi harapan bangsa serta memiliki harkat dan martabat yang juga harus di hormati dan Hak Asasi Manusia yang harus dilindungi.

Selain itu juga, anak-anak penyandang disabilitas juga harus mengetahui serta mendapatkan pendidikan dan pengetahuan tentang apa-apa saja yang menjadi hak-nya. Sehingga anak-anak disabilitas tetap merasa dihargai kehadirannya dan mampu untuk menuntut hak-hak nya apabila hak-hak yang melekat pada dirinya diabaikan oleh orangorang sekitarnya.

\section{Metode Pelaksanaan}

\section{Metode Pelaksanaan}

Pendampingan dilakukan kepada siswa-siswi Sekolah Luar Biasa Sri Mujinab Kota Pekanbaru tentang hak-hak aksessibilitas yang dimiliki oleh disabilitas berdasarkan Undang-Undang Nomor 19 Tahun 2011 tentang Pengesahan Convention on the Rights of Persons with Disabilities, hak-hak yang melekat pada anak-anak disabilitas, serta Peraturan Daerah Nomor 18 Tahun 2013 tentang Perlindungan dan Pemberdayaan Penyandang Disabilitas di Provinsi Riau.

Diskusi dan tanya jawab dengan pihak sekolah, yang dalam hal ini dilakukan dengan salah satu guru Sekolah Luar Biasa Sri Mujinab yaitu Bapak Hanafi mengenai halhal yang berkaitan dengan kurangnya fasilitas dan sarana prasarana serta pelayanan yang diberikan oleh Pemerintah dan Swasta terhadap hak-hak bagi anak-anak kaum disabilitas saat ini. 


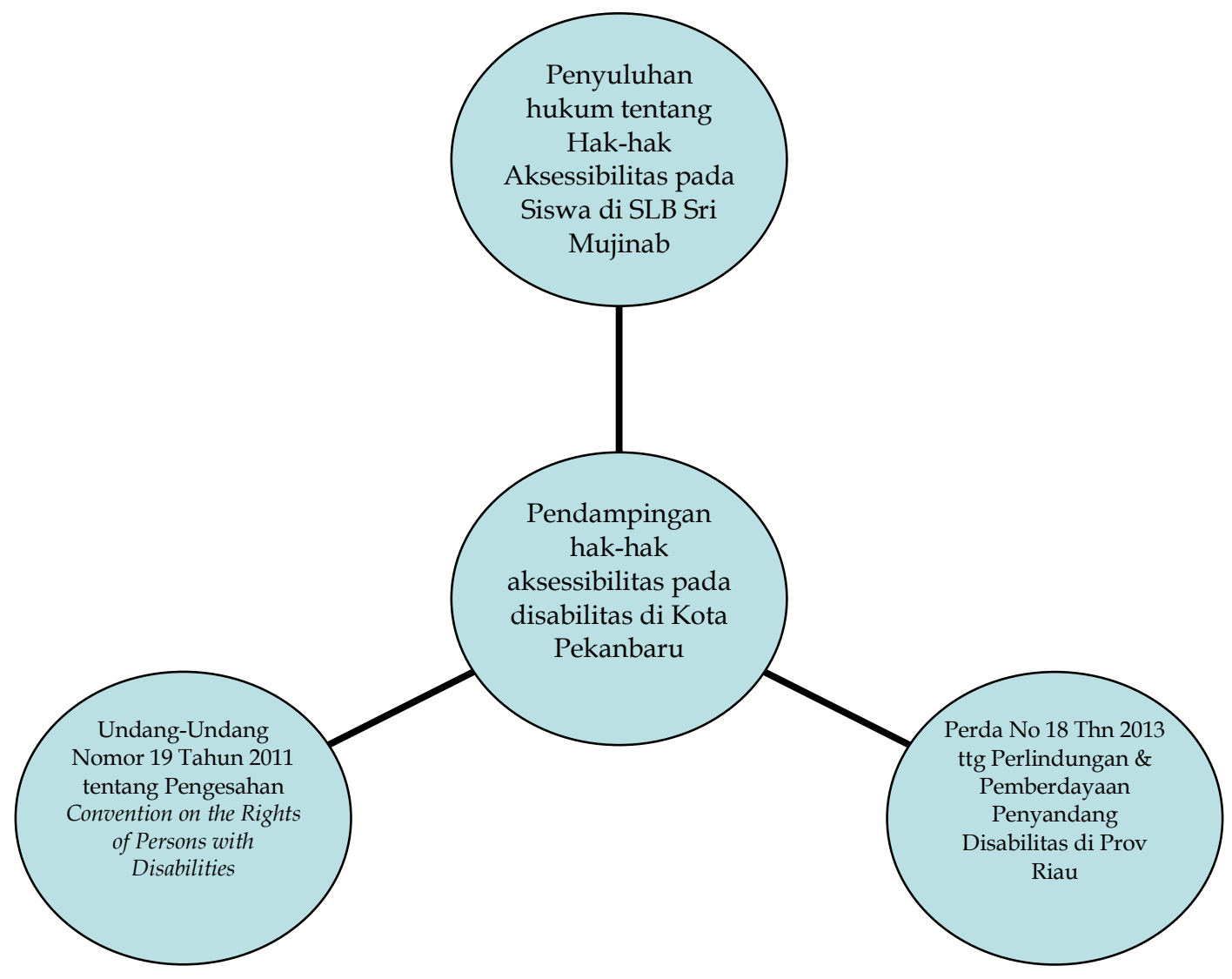

\section{Jadwal kegiatan}

Tahapan dan rangkaian program Pengabdian masyarakat dan waktu pelaksanaannya sebagai berikut

\begin{tabular}{|c|c|c|c|c|c|c|c|c|c|c|c|}
\hline \multirow{2}{*}{ No } & \multirow{2}{*}{ Jenias kegiatan } & \multicolumn{3}{|c|}{ September } & \multicolumn{3}{|c|}{ Oktober } & \multicolumn{4}{|c|}{ November } \\
\hline & & \begin{tabular}{l|l}
1 & 2
\end{tabular} & 3 & 4 & 1 & $2 \mid 3$ & \begin{tabular}{|l|l}
3 & 4
\end{tabular} & 1 & 2 & & 4 \\
\hline 1 & Koordinasi dengan Pihak Sekolah & & & & & & & & & & \\
\hline 2 & $\begin{array}{l}\text { Pembuatan dan Pembagian undangan serta } \\
\text { Persiapan tempat Pendampingan }\end{array}$ & & & & & & & & & & \\
\hline 3 & Pelaksanaan Kegiatan Penyuluhan & & & & & & & & & & \\
\hline 4 & $\begin{array}{l}\text { Pendampingan dan advokasi persoalan } \\
\text { disabilitas }\end{array}$ & & & & & & & & & & \\
\hline 5 & Monitoring dan evaluasi kegiatan mitra & & & & & & & & & & \\
\hline 6 & Pembuatan Laporan & & & & & & & & & & \\
\hline 7 & $\begin{array}{l}\text { Medsos, Poster, Prosiding dan Jurnal } \\
\text { pengabdian masyarakat atau luaran lainnya }\end{array}$ & & & & & & & & & & \\
\hline
\end{tabular}




\section{Hasil dan Pembahasan}

Dari penyuluhan hukum yang telah dilakukan di SLB Sri Mujinab Kota Pekanbaru dengan jumlah peserta 40 siswa-siswi dan 10 orang guru pendamping. Hampir semua siswa-siswi berperan aktif dan antusias menyimak setiap pemaparan yang diberikan oleh Tim Penyuluh. Walau dengan keterbatasan yang mereka miliki, tetapi tim penyuluh sudah membuat terobosan atau strategi yang baru agar memudahkan berkomunikasi dengan mereka, terutama bagi kaum tuna rungu dan tuna wicara.

Strategi yang dilakukan oleh tim penyuluh dalam hal berkomunikasi dengan siswasiswi tuna rungu dan tuna wicara adalah:

1. Tim penyuluh meminta bantuan Rafiqi Ulfa (Alumni Sekolah Luar Biasa) yang dalam hal ini beliau sebagai penerjemah yang menggunakan bahasa isyarat. Setiap uraian yang disampaikan oleh tim penyuluh kepada peserta di terjemahkan oleh Rafiqi Ulfa. Rafiqi Ulfa juga bagian dari kaum disabilitas, yang dalam kekurangan dan keterbatasannya sebagai tuna rungu dan tuna wicara.

2. Tim penyuluh memaparkan uraiannya dengan lebih banyak menggunakan bantuan audio visual, yakni membuat film dan menontonkannya kepada siswasiswi terhadap prestasi-prestasi kaum disabilitas yang ada diseluruh dunia, serta fasilitas-fasilitas serta hak-hak kaum disabilitas yang dijamin oleh Negara. Hal ini lebih memudahkan mereka dalam memahami maksud dan tujuan penyuluhan yang dilakukan;

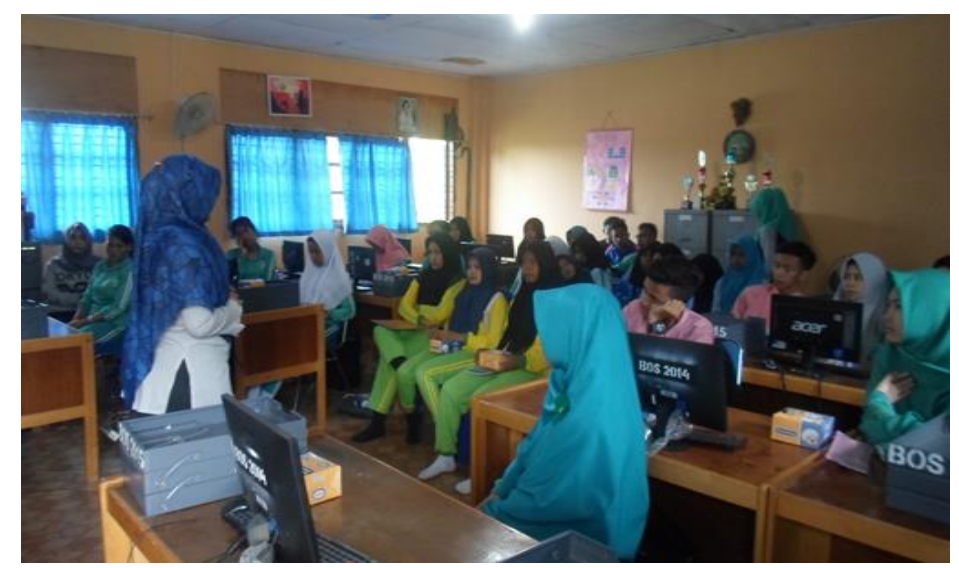

Dengan keterbatasan yang dimiliki oleh peserta, maka dalam sesi Tanya jawab, tim penyuluh lebih meminta bantuan dari salah satu guru Sekolah Luar Biasa yang dalam hal ini dibantu oleh Bapak Hanafi untuk berdiskusi mengenai pelaksanaan dan perlindungan hak-hak bagi anak-anak disabilitas.

Dalam pemaparannya, beliau mengatakan bahwa masih banyak kekurangan yang diberikan oleh pemerintah. Salah satu contoh ketika siswa-siswinya dikirim ke Luar Negeri untuk mengikuti olimpiade dalam berbagai bidang, dan saat berada di Pesawat, tidak ada pelayanan khusus yang diberikan oleh Pramugari pada anak-anak disabilitas. Terlebih ketika anak-anak tersebut membutuhkan bantuan untuk ke kamar kecil. 
Selain itu, beberapa fasilitas umum belum dapat memberikan kemudahan bagi anakanak disabilitas, seperti di perpustakaan kota maupun provinsi belum banyak memiliki buku-buku dengan tulisan Braille untuk tuna netra. Dalam hal pemenuhan hak politik kaum disabilitas, banyak siswa-siswi Sekolah Luar Biasa yang walaupun masih duduk di jenjang pendidikan Sekolah Dasar dan Sekolah Menengah Pertama, tapi usia mereka sudah memenuhi kriteria sebagai warga negara yang memiliki hak memilih. Tetapi pada pelaksanaan Pemilihan Umum tahun 2019 ini, banyak hak-hak politik mereka yang terabaikan. Terutama dalam fasilitas, pelayanan dan sarana prasarana tidak disediakan oleh Komisi Penyelenggara Pemilihan Umum, yang padahal dalam Undang-Undang pemilihan Umum mengatur tentang pelayanan khusus yang harus diberikan kepada kaum disabilitas.

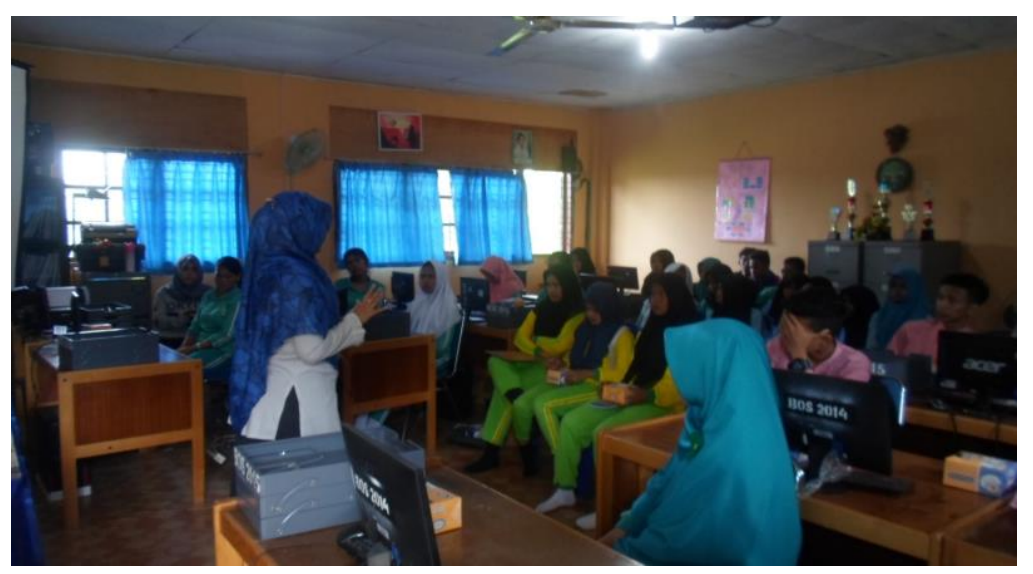

Upaya penyediaan sarana dan layana yang memudahkan merupakan gerakan mendasar yang perlu dipahami dan disadari, agar pemerintah dan masyarakat Indonesia dapat melakukan aksi yang lebih akomodatif terhadap perolehan dan pemenuhan hak penyandang disabilitas. Untuk itu, siapa penyandang disabilitas serta bentuk sarana dan layanan apa yang memudahkan mereka perlu dikenali, dipahami, dan dipenuhi sebagaimana diuraikan dalam tabel berikut ini:

Tabel 1: Jenis Disabilitas

\begin{tabular}{|c|c|c|c|}
\hline JENIS & GANGGUAN & CIRI-CIRI & SARANA \& PRASARANA \\
\hline Tuna Netra & Penglihatan & $\begin{array}{l}\text { Sering menabrak } \\
\text { dan sulit dalam } \\
\text { arah }\end{array}$ & $\begin{array}{l}\text { Akses terhadap suara, bau, } \\
\text { raba, dan sentuh }\end{array}$ \\
\hline $\begin{array}{l}\text { Tuna } \\
\text { Rungu/Wicara }\end{array}$ & $\begin{array}{l}\text { Pendengaran/ } \\
\text { bicara }\end{array}$ & $\begin{array}{l}\text { Sering menatap } \\
\text { dan sulit mengerti }\end{array}$ & $\begin{array}{l}\text { Lihat, gerakan, mimic, } \\
\text { komunikasi tulis, ucapan jelas }\end{array}$ \\
\hline Tuna Grahita & $\begin{array}{l}\text { Kecerdasan di } \\
\text { bawah rata-rata }\end{array}$ & $\begin{array}{l}\text { Suka meniru dan } \\
\text { lambat }\end{array}$ & $\begin{array}{l}\text { Pengulangan, pembiasaan, } \\
\text { pengawasan, bicara singkat } \\
\text { diikuti contoh, advokasi } \\
\text { sepanjang hidup }\end{array}$ \\
\hline Tuna Daksa & Gerak & $\begin{array}{ll}\text { Sulit } & \text { berpindah } \\
\text { ruangan } \& \text { sulit }\end{array}$ & $\begin{array}{lrr}\text { Lantai } & \text { rata, ruangan lebar, } \\
\text { tidak } & \text { ada } & \text { perbedaan }\end{array}$ \\
\hline
\end{tabular}




\begin{tabular}{|l|l|l|l|}
\hline & & menjangkau benda & $\begin{array}{l}\text { ketinggian, letak barang mudah } \\
\text { di jangkau }\end{array}$ \\
\hline Autism & $\begin{array}{l}\text { Suka menyendiri } \\
\text { dan sulit } \\
\text { berinteraksi }\end{array}$ & $\begin{array}{l}\text { Komunikasi dengan gambar } \\
\text { dan tulisan, pendekatan, } \\
\text { pengulangan, pelibatan }\end{array}$ \\
\hline
\end{tabular}

Berdasarkan dari hasil kegiatan ini, tim penyuluh menyediakan pendampingan gratis bagi anak-anak disabilitas yang membutuhkan bantuan hukum. Pendampingan ini dilakukan dengan maksud agar anak-anak disabilitas tetap merasa nyaman dan di lindungi oleh segala bentuk pelanggaran hak-hak asasinya. Selain daripada itu, diharapkan tidak ada lagi perlakuan diskriminasi yang dirasakan oleh anak-anak disabilitas.

Undang-Undang Nomor 19 Tahun 2011 tentang Pengesahan Convention on the Rights of Persons with Disabilities, memuat 8 (delapan) prinsip yang menjadi dasar konvensi tersebut, yakni:

a. Penghormatan pada martabat yang melekat, otonomi individu; termasuk kebebasan untuk menentukan pilihan, dan kemerdekaan seseorang;

b. Nondiskriminasi;

c. Partisipasi penuh dan efektif dan keikutsertaan dalam masyarakat;

d. Penghormatan pada perbedaan dan penerimaan penyandang disabilitas sebagai bagian dari keragaman manusia dan kemanusiaan;

e. Kesetaraan kesempatan;

f. Aksesibilitas;

g. Kesetaraan antara laki-laki dan perempuan;

h. Penghormatan atas kapasitas yang terus berkembang dari penyandang disabilitas anak dan penghormatan pada hak penyandang disabilitas anak untuk mempertahankan identitas mereka.

\section{Kesimpulan}

Dari pelaksanaan penyuluhan hukum tentang Peningkatan Pemahaman dan Pendampingan terhadap Hak-hak Aksessibilitas pada Anak Disabilitas di Kota Pekanbaru, dapat disimpulkan:

1. Dari penyuluhan hukum tentang Peningkatan Pemahaman dan Pendampingan terhadap Hak-hak Aksessibilitas pada Anak Disabilitas di Kota Pekanbaru khususnya siswa-siswi Sekolah Luar Biasa Sri Mujinab Pekanbaru dapat mengetahui hak dan kewajibannya yang diberikan oleh negara;

2. Dari penyuluhan hukum yang telah dilaksanakan tersebut dapat meningkatkan pemahaman dan pengetahuan peserta tentang hak-hak mereka dan fasilitas, sarana prasarana, dan pelayanan khusus yang seharusnya mereka peroleh;

3. Dari penyuluhan hukum yang telah dilaksanakan tersebut dapat memberikan pengetahuan kepada pihak sekolah terutama guru Sekolah Luar Biasa Sri Mujinab 
terhadap upaya yang dapat dilakukan apabila terjadi pelanggaran hak terhadap anakanak disabilitas yang dalam hal ini siswa-siswi mereka.

\section{Saran}

1. Agar pihak sekolah selalu melakukan pengawasan terhadap para siswa-siswi, anak disabilitas terhadap pelaksanaan dan perlindungan hak-hak mereka, agar segala hakhak mereka terpenuhi dan tidak terjadi diskriminasi;

2. Membangun komunikasi yang baik antara pihak keluarga dan pihak sekolah tentang perkembangan jiwa dan pergaulan anak-anak disabilitas agar mereka tetap dapat tumbuh dan berkembang seperti yang terjadi terhadap anak-anak pada umumnya. 


\section{Daftar Pustaka}

Atmasasmita, Romli. (2007). Teori dan Selekta Kriminologi. Bandung: Refika Aditama.

Marliana. (2009). Peradilan Pidana Anak di Indonesia (Pengembangan Konsep Diversi dan Restrorative Justice). Bandung: Refika Aditama.

Nashriana. (2001). Perlindungan Hukum Pidana Bagi Anak di Indonesia. Jakarta: Raja Grafindo Persada.

Prinst, Darwan. (1997). Hukum Anak Indonesia. Bandung: Citra Aditya Bakti.

Undang-Undang Dasar Negara Republik Indonesia Tahun 1945.

Undang-Undang Nomor 35 Tahun 2014 tentang Perlindungan Anak.

Undang-Undang Nomor 39 Tahun 1999 tentang Hak Asasi Manusia.

Undang-Undang Nomor 19 Tahun 2011 tentang Pengesahan Convention on the Rights of Persons with Disabilities.

Peraturan Daerah Nomor 18 Tahun 2013 tentang Perlindungan dan Pemberdayaan Penyandang Disabilitas di Provinsi Riau. 